\title{
PENGEMBANGAN SUMBER BELAJAR GEOGRAFI BERBASIS WEBLOG PADA MATERI PEMBELAJARAN GEOGRAFI KELAS X DI SMA NEGERI 8 PADANG
}

\author{
Refika Refina ${ }^{1}$, Yurni Suasti ${ }^{2}$, Nofrion ${ }^{2}$ \\ Program Studi Pendidikan Geografi, \\ Fakultas Ilmu Sosial, Universitas Negeri Padang \\ Email: refikarefinageografi28@gmail.com
}

\begin{abstract}
Abstrak
Penelitian ini bertujuan untuk :1) mengembangkan sumber belajar geografi berbasis weblog pada materi kelas X SMA, 2) mengetahui kevalidan sumber belajar geografi berbasis weblog, 3) mengetahui kepraktisan sumber belaja geografi berbasis weblog. Jenis penelitian ini adalah penelitian pengembangan (Research and Development) dengan mengadaptasi model ASSURE. Model dikembangkan dalam enam tahapan yaitu a)analisis peserta didik, b) merumuskan tujuan pembelajaran, c) memilih metode, media dan bahan ajar, d) memanfaatkan media dan materi, e) mengembangkan peran serta peserta didik, f) evaluasi dan revisi. Validasi dilakukan oleh ahli perangkat pembelajaran, ahli materi dan media. Kepraktisan dilakukan oleh dua orang guru geografi dan 30 orang siswa SMAN 8 Padang. Hasil penelitian menunjukan bahwa sumber belajar geografi berbasis weblog sangat valid dan sangat praktis. Ahli perangkat pembelajaran menilai sangat valid dengan nilai akhir 90,74\%, ahli materi menilai sangat valid dengan nilai akhir $90,56 \%$, dan ahli media menilai sangat valid dengan nilai akhir $85,42 \%$. Guru geografi menilai sangat praktis dengan nilai akhir 83,04\%, dan siswa kelas X IPS SI SJ 2 menilai sangat praktis dengan nilai akhir $83,47 \%$.
\end{abstract}

Kata Kunci: Sumber Belajar Geografi, Weblog, Assure.

\begin{abstract}
Abstrack
The purpose of this research was to identify: 1) develop weblog-based geography learning resources on class $X$ high school, 2) to know the validity of weblog based geographic learning resources, 3) to know the practicability of geographical resources based on weblog. This research was research and development (Research and Development) by adapting the ASSURE model. This mode can be increase in the 6 stages: a) analyze learners, b) state objectives, c) select methods, media and materials, $d$ ) utilize materials, e) require learners participation, f) evaluated and revise. Validation is done by the learning device expert, the matter and media expert. practicality has been done by 2 geography teachers and 30 students of SMAN 8 Padang. The results show that the source of weblog based learning weblog is very valid and very practicability. Expert learning tool rate is very valid with final score $90,74 \%$, matter expert rate very valid with final value 90,56\%, and media expert rate very valid with final value $85,42 \%$. The geography teacher rate is very practicability with a final grade of $83.04 \%$, and the student class X IPS SI SJ 2 rate is very practicability with a final value of $83.47 \%$.
\end{abstract}

Keywords: geography learning resources, Weblog, Assure.

\footnotetext{
${ }^{1}$ Mahasiswa Program Studi Pendidikan Geografi untuk wisuda Maret 2018

${ }^{2}$ Dosen Jurusan Geografi Fakultas Ilmu Sosial Universitas Negeri Padang. Dra Yurni Suasti, M.Si. Nofrion, S.Pd, M.Pd
} 


\section{PENDAHULUAN}

Proses belajar dalam aktivitas pendidikan merupakan proses yang terjadi antara pengajaran dan siswa serta dipengaruhi oleh hubungan yang ada dalam proses belajar mengajar. Jika belajar adalah suatu proses aktif dalam membangun pengetahuan maka dalam belajar akan terjadinya pembelajaran. Pembelajaran seharusnya mampu mengembangkan potensi siswa dengan optimal yang salah satunya dilakukan dengan pemberian tugas/soal yang menantang (Nofrion \& Bayu, 2018). Hal ini bisa mengembangkan keterampilan berfikir tingkat tinggi di kalangan siswa (Nofrion, 2018).

Pembelajaran adalah hubungan interaksi antara peserta didik dengan guru dan sumber belajar pada suatu lingkungan belajar. Pembelajaran harus diadakan secara interaktif, inspiratif, menyenangkan, menantang dan memotivasi siswa untuk mengembangkan potensi, kreativitas dan kemandiriannya (Nofrion 2017: 163). Pembelajaran sebagai interaksi pendidik dengan peserta didik dan sumber belajar yang menyebabkan adanya interaktif yang memotivasi peserta didik dan berpartisipasi aktif dalam suatu wadah komunikasi untuk mencapai tujuan dan target yang diinginkan.

Pada setiap pembelajaran dibutuhkan interaksi antara pendidik dengan peserta didik dan sumber belajar, baik secara langsung (tatap muka) ataupun tidak langsung (menggunakan sumber belajar atau media pembelajaran) yang berisikan serangkaian peristiwa yang dirancang, disusun untuk mempengaruhi dan mendukung terjadinya proses belajar yang membahas tentang aspek dan fenomena geografi yang ada pada suatu lingkungan.

Salah satu penunjang dalam proses pembelajaran adalah sumber belajar. Menurut Asosiasi Teknologi Komunikasi Pendidikan/AECT dalam Warsita (2008:209) sumber belajar adalah meliputi semua sumber, baik berupa data, barang atau benda yang dapat digunakan untuk memberi fasilitas (kemudahan) belajar bagi peserta didik.

Kemajuan ilmu pengetahuan dan teknologi memberikan banyak pengaruh salah satunya dalam pemecahan masalah belajar. Dalam upaya pemecahan masalah belajar, teknologi menggunakan 3 prinsip dasar, yaitu: berorientasi pada si belajar, pendekatan sistem, dan pemanfaatan sumber belajar secara luas dan maksimal (Soeharto 1995:10). Untuk memanfaatkan sumber belajar secara luas dan maksimal maka menjadikan suatu tantangan dan dorongan bagi dunia pendidikan untuk melakukan upaya-upaya pembaharuan dengan memanfaatkan hasil-hasil teknologi dalam pembelajaran dengan menawarkan berbagai kemudahan dalam memperoleh informasi melalui jaringan internet

Seiring dengan kemajuan zaman, perkembangan teknologi dibidang informasi dan komunikasi yang terhubung dengan penggunaan internet juga berpengaruh besar dibidang 
pendidikan. Penggunaan buku cetak yang biasanya menjadi sumber belajar utama telah mengalami perubahan menjadi buku-buku online yang menggunakan fasilitas internet dalam mengaksesnya. Internet menjadi salah satu sarana dalam pengembangan weblog sebagai sumber belajar geografi.

Keberadaan internet yang sudah merata dapat memberikan dampak positif dalam pengembangan sumber belajar geografi.

Weblog atau yang lebih dikenal dengan sebutan blog adalah jenis situs web yang dikembangkan dan dikelola oleh seorang individu dengan menggunakan perangkat lunak (software) online atau platform host yang sangat mudah untuk pengguna blog dengan ruang untuk menulis. Selain itu blog juga digunakan bagi pembaca untuk memberikan umpan balik dalam memberikan komentar. (Solomon\&Schrum,2011:15).

Dengan demikian kelebihan blog sebagai media dan sumber belajar adalah blog dapat diakses oleh para siswa kapan saja dengan menggunakan handphone atau smartphone.

Berdasarkan Permendikbud No 22 Tahun 2016 tentang Standar Proses, salah satu prinsip pengembangan sumber belajar adalah pemanfaatan teknologi informasi dan komunikasi untuk meningkatkan efisiensi dan aktivitas pembelajaran. Selain itu, guru tidak lagi menjadi satu-satunya sumber belajar. Sesuai dengan prinsip diatas, dibutuhkanlah sebuah sumber belajar yang dapat digunakan untuk memberi fasilitas (kemudahan) belajar bagi peserta didik. Salah satu contoh sumber belajar yang mudah diakses peserta didik dimanapun yang berbasiskan teknologi informasi dan media adalah dalam bentuk weblog. Untuk itu, penelitian ini bertujuan untuk mengembangkan sumber belajar geografi berbasis weblog.

\section{METODE PENELITIAN}

Penelitian ini merupakan jenis penelitian dan pengembangan (research and development/R\&D). Penelitian pengembangan yang dilakukan mengikuti standar Kerangka Kualifikasi Nasional Indonesia (KKNI) level VI untuk sarjana $\mathrm{S} 1$ yaitu; mengaplikasikan, mengkaji, membuat desain, memanfaatkan IPTEKS dan menyelesaikan masalah. Menurut Sugiyono (2008) penelitian dan pengembangan adalah metode penelitian yang digunakan untuk menghasilkan produk tertentu dan menguji keefektivan produk tersebut.

Desain pengembangan yang digunakan yaitu Model Pengembangan ASSURE dengan langkah pengembanganya yaitu (1) Analyze Learners (analisis karakteristik siswa), (2) State Standars and Objective (merumuskan tujuan pembelajaran), (3) Select Methods, Media, and Materials (memilih metode, media, dan bahan ajar), (4) Utilize Materials (memanfaatkan material), (5) Requires Learner Participation (mengembangkan peran serta peserta didik), (6) Evaluate and Revise (mengevaluasi dan revisi)

Objek penelitian adalah sumber belajar Geografi berbasis weblog pada 
materi kelas X SMA. Subjek penelitian adalah guru geografi dan siswa kelas $\mathrm{X}$ IPS SI SJ 2.

Teknik analisis uji data yang digunakan adalah analisis validitas dan kepraktisan weblog yang dikembangkan. Uji validitas dilakukan oleh tenaga ahli, sedangkan kepraktisan dinilai oleh guru dan siswa dengan menggunakan kuesioner dalam bentuk skala Likert 1-4.

Tabel 1 Kategori validitas dan kepraktisan

\begin{tabular}{|l|l|l|}
\hline No & Nilai & Kriteria \\
\hline 1 & $80 \%<\mathrm{x} \leq 100 \%$ & $\begin{array}{l}\text { Sangat } \\
\text { Valid/Sangat } \\
\text { Praktis }\end{array}$ \\
\hline 2 & $60 \%<\mathrm{x} \leq 80 \%$ & Valid/Praktis \\
\hline 3 & $40 \%<\mathrm{x} \leq 60 \%$ & $\begin{array}{l}\text { Cukup } \\
\text { Valid/Cukup } \\
\text { Praktis }\end{array}$ \\
\hline 4 & $20 \%<\mathrm{x} \leq 40 \%$ & $\begin{array}{l}\text { Kurang Valid/ } \\
\text { Kurang Prakis }\end{array}$ \\
\hline 5 & $0 \%<\mathrm{x} \leq 20 \%$ & $\begin{array}{l}\text { Tidak } \\
\text { Valid/Tidak } \\
\text { Praktis }\end{array}$ \\
\hline
\end{tabular}

Sumber: Dimodifikasi dari Riduwan (2009)

\section{HASIL PENELITIAN DAN PEMBAHASAN}

\section{Tahapan Prosedur Pengembangan Penelitian}

\section{a. Analyze Learners (Analisis Peserta} Didik)

Analisis pesera didik meliputi (1) sumber belajar yang dipakai saat proses pembelajaran, (2) tingkat pengetahuan peserta didik dengan teknologi. Analisisdilakukan dengan dua cara, yaitu pertama melakukan diskusi bersama guru geografi di sekolah. Hasil dari diskusi bersama guru geografi adalah siswa kelas X SMA Negeri 8 Padang sudah terbiasa dengan penggunaan komputer/laptop, dan smartphone. Menurut guru, pengunaan smartphone oleh siswa membawa pengaruh buruk terhadap siswa dalam proses pembelajaran, hal tersebut didukung oleh sekolah agar peserta didik tidak membawa smartphone mereka ke sekolah karena banyak siswa yang lebih terfokus menggunakan smartphone saat jam pembelajaran sehingga tidak tercapainya tujuan pembelajaran.

Berdasarkan pengamatan lapangan dan wawancara ditemukan bahwa sumber belajar yang digunakan peserta didik terbatas pada penggunaan buku paket yang disediakan. Buku paket ini digunakan dalam bentuk pembelajaran berkelompok, karena jumlah yang tidak sesuai dengan peserta didik. Selain itu, peserta didik juga menggunakan LKS MGMP. Artinya, sumber belajar yang digunakan masih sangat terbatas. Padahal, dengan adanya kemudahan teknolgi didukung dengan siswa yang memiliki tingkat pemahaman yang cukup baik mengenai internet, guru bisa mengembangkan teknologi sebagai sumber belajarsecara baik.

\section{b. State Objective (Merumuskan Tujuan Pembelajaran}

Langkah berikut setelah analisis peserta didik adalah merumuskan tujuan pembelajaran. Tujuan umum dari pengembangan sumber belajar geogafi berbasis blog ini adalah memfasilitasi peserta didik yang akrab dengan laptop 
dan smartphone supaya fasilitas yng diberikan orang tua peserta didik dapat dimanfaatkan secara optimal. Tujuan khusus pengembangan sumber belajar berbasis blog mengacu pada silabus kurikulum 2013 revisi mata pelajaran Geografi Kelas X.

\section{c. Select Intructional Methods, Media} and Materials (Memilih Metode, Media, dan Bahan Ajar)

Metode yang digunakan adalah tutorial. Maksudnya,weblog yang dirancang dilengkapi dengan langkahlangkah penggunaan fitur-fitur dalam blog. Maka dengan menggunakan weblog, peserta didik bisa belajar mandiri. Media yang digunakan sebagai sumber belajar siswa adalah weblog, karena pemahaman siswa terhadap internet yang baik memudahkan siswa mendapatkan sumber belajar geografi melalui pengaplikasian komputer/laptop dan smartphone siswa. Materi yang dipilih berupa keseluruhan materi kelas $\mathrm{X}$ SMA yang dikembangkan dalam bentuk Silabus, Rancangan Perencanan Pembelajaran (RPP), Bahan Ajar, Lembar Kerja Peserta Didik (LKPD), dan Power Point (PPT). Penyusunan sumber belajar tersebut telah disesuaikan dengan kebutuhan guru dan siswa berdasarkan kurikulum 2013 revisi.Selanjutnya melakukan validasi terhadap RPP, Bahan Ajar dan PPT.

\section{d. Utilize Media and Materials (Memanfaatkan Media dan Materi)}

Setelah dilakukan validasi terhadap perangkat pembelajaran, materi, dan Power Point (PPT) ditentukan jenis teknologi pendukung yang dibutuhkan untuk dapat mendukung penggunaan sumber belajar geografi dengan baik. Teknologi pendukung yang diperlukan yaitu Internet. Sumber belajar geografi kelas X SMA diupload kedalam sebuah blog yang bertujuan agar guru dan peserta didik mudah mengaksesnya. Selain internet teknologi pendukung lainnya yaitu berupa komputer/laptop, dan smartphone yang dapat terhubung ke internet. Penilaian dari ahli media juga diperlukan untuk menguji atau memberikan penilaian terhadap komponen blog.

\section{e. Require Learner Participation (Mengembangkan Peran Serta Pesrta Didik}

Pada tahap ini, siswa akan diminta untuk belajar menggunakan sumber belajar weblog yang telah disediakan. Untuk melihat partisipasi peserta didik dapat dilakukan uji coba lapangan di kelas. Uji coba produk dilakukan pada hari selasa tanggal 28 November 2017 di kelas X IPS SI-SJ2 SMA Negeri 8 Padang yang berjumlah 30 orang siswa. Sebelum blog diujicobakan, peneliti memastikan bahwa sekolah telah mengizinkan siswa dalam membawa smartphone mereka. Laptop dan smartphone tersebut digunakan saat mata pelajaran geografi. Setelah itu pembelajaran dilakukan seperti biasa didalam kelas dengan bantuan sumber belajar geografi berbasis blog dengan mengakses

http://sbgeografismax.blogspot.co.idmel alui jaringan internet pribadi siswa dan hotspot portabel dari peneliti. 


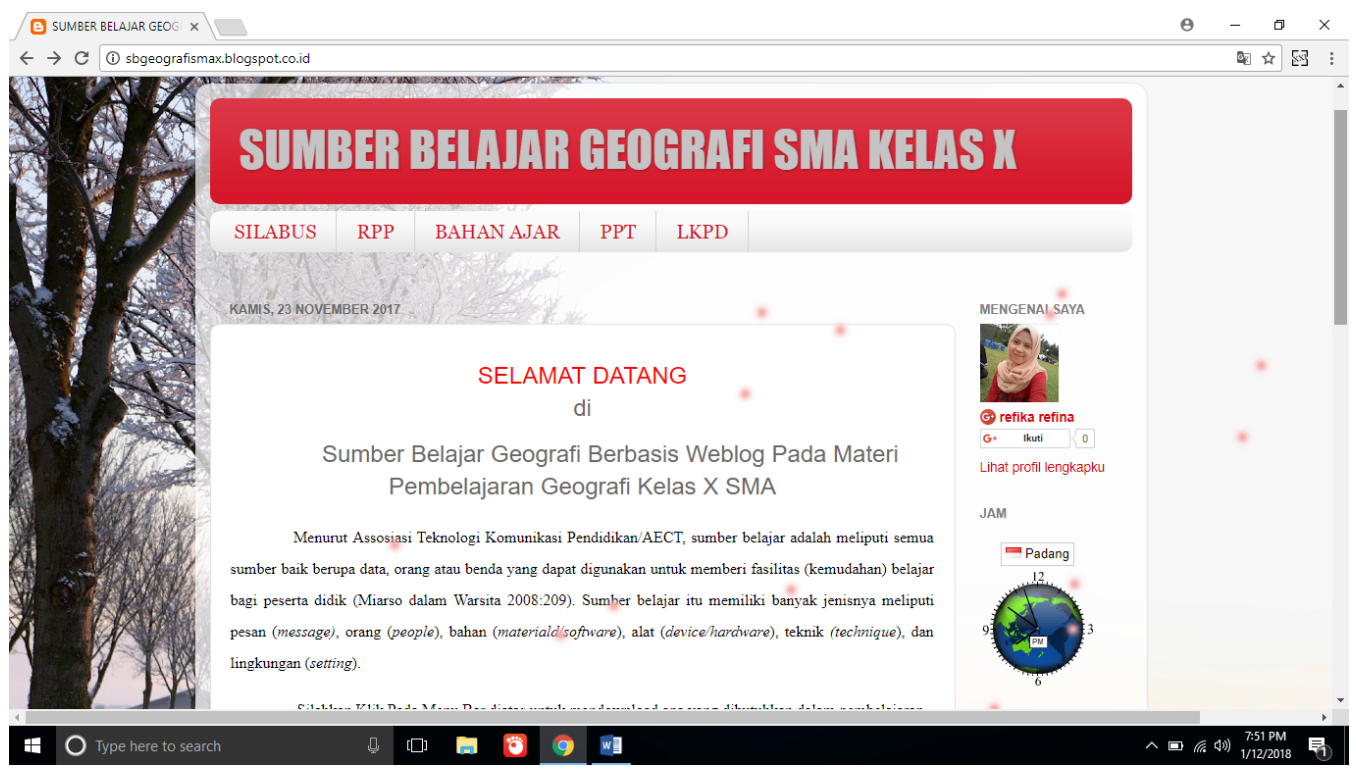

Gambar 1 : Beranda Weblog

Sumber: http://sbgeografismax.blogspot.co.id/

Setelah siswa mencoba belajar menggunakan sumber belajar geografi berbasis weblog tersebut, siswa diminta mengisi angket yang diberikan untuk mengutarakan penilaian dan pendapat/saran terhadap weblog geografi. Tujuan dari penilaian ini untuk mengetahui kepraktisan sumber belajar berbasis weblog terkait aspek kemudahan penggunaan, efesiensi waktu dan manfaat dari blog.

\section{f. Evaluate and Revise (Evaluasi dan Revisi)}

Evaluasi dan revisi dalam sumber belajar berbasis ini dilakukan pada setiap pokok bahasan. Komponen yang dievaluasi dan revisi adalah perangkat pembelajaran, materi, dan media.

\section{Analisis Data Validitas}

Validitas sumber belajar geografi berbasis weblog dilihat dari: (a) perangkat pembelajaran, (b) materi, dan (c) media.

\section{a. Analisis Data Validasi Perangkat Pembelajaran}

Tabel 2 Hasil Penilaian Ahli Perangkat Pembelajaran (RPP)

\begin{tabular}{|c|c|c|}
\hline Aspek & $\begin{array}{c}\text { Nilai } \\
\text { Akhir }\end{array}$ & Kriteria \\
\hline $\begin{array}{c}\text { Kelayakan } \\
\text { Isi }\end{array}$ & 95,00 & Sangat valid \\
\hline Kebahasaan & 83,33 & Sangat valid \\
\hline Penyajian & 95,83 & Sangat valid \\
\hline Kegrafikan & 81,25 & Sangat valid \\
\hline & $\mathbf{9 0 , 7 4}$ & $\begin{array}{c}\text { Sangat } \\
\text { valid }\end{array}$ \\
\hline
\end{tabular}

Sumber : Olahan Data Primer 2017

Berdasarkan tabel 2, diketahui penilaian dalam aspek kelayakan isi (95\%), kebahasaan (83\%), penyajian $(95,83 \%)$, kegrafikan $(81,25 \%)$ dengan nilai akhir 90,74\%. Berdasarkan penilaian validator perangkat pembelajaran maka sumber belajar 
geografi berbasis weblog termasuk kategori sangat valid pada semua aspek perangkat pembelajaran (RPP).

b. Validasi Data oleh Ahli Materi ( Bahan Ajar, LKPD, PPT)

Tabel 3 Hasil Penilaian Ahli Materi

\begin{tabular}{|c|c|c|}
\hline Aspek & $\begin{array}{c}\text { Nilai } \\
\text { Akhir }\end{array}$ & Kriteria \\
\hline Kelayakan Isi & 92,86 & Sangat valid \\
\hline Kebahasaan & 89,88 & Sangat valid \\
\hline Penyajian & 89,29 & Sangat valid \\
\hline Kegrafikan & 88,78 & Sangat valid \\
\hline & $\mathbf{9 0 , 5 6}$ & Sangat valid \\
\hline
\end{tabular}

Sumber : Olahan Data Primer 2017

Berdasarkan tabel di atas, penilaian dalam aspek kelayakan isi (92,86\%), kebahasaan (89,88\%), penyajian $(89,29 \%)$, kegrafikan $(88,78 \%)$ dengan nilai akhir 90,56\%. Berdasarkan penilaian ahli perangkat materi maka sumber belajar geografi berbasis blog termasuk kategori sangat valid pada semua aspek materi

\section{c. Validasi Data Oleh Ahli Media}

Tabel 4 Hasil Penilaian Ahli Media

\begin{tabular}{|c|c|c|}
\hline Aspek & $\begin{array}{c}\text { Nilai } \\
\text { Akhir }\end{array}$ & Kriteria \\
\hline Tampilan & 85,71 & Sangat valid \\
\hline Tipografi & 82,14 & Sangat valid \\
\hline Pemograman & 90,00 & Sangat valid \\
\hline $\begin{array}{c}\text { Kelengkapan } \\
\text { Media }\end{array}$ & 85,00 & Sangat valid \\
\hline & $\mathbf{8 5 , 4 2}$ & Sangat valid \\
\hline
\end{tabular}

Sumber : Olahan Data Primer 2017

Dari tabel di atas dapat dilihat bahwa penilaian aspek tampilan (85,71\%), tipografi (82,14\%), pemograman $(90,00 \%)$, kelengkapan media $(85,00 \%)$ dengan nilai akhir $85,2 \%$. Berdasarkan penilaian ahli media maka sumber belajar geografi berbasis blog termasuk kategori sangat valid pada media.

\section{Analisis Data Kepraktisan}

\section{a. Analisis Data Kepaktisan Oleh Siswa}

Tabel 5 Hasil Penilaian Kepraktisan Siswa

\begin{tabular}{|c|c|c|}
\hline Aspek & $\begin{array}{c}\text { Nilai } \\
\text { Akhir }\end{array}$ & Kriteria \\
\hline Kelayakan Isi & 83,83 & Sangat praktis \\
\hline Efisiensi Waktu & 85,42 & Sangat praktis \\
\hline Manfaat & 82,33 & Sangat praktis \\
\hline & $\mathbf{8 3 , 4 7}$ & $\begin{array}{c}\text { Sangat } \\
\text { praktis }\end{array}$ \\
\hline
\end{tabular}

Sumber : Olahan Data Primer 2017

Berdasarkan tabel 5 dapat diketahui bahwa penilian dalam aspek kemudahan penggunaan $(83,83 \%)$ mendapatkan kategori sangat praktis, aspek efesiensi waktu $(85,42 \%)$ dengan kategori sangat praktis, dan aspek manfaat $(82,33 \%)$ sangat praktis dengan nilai akhir 83,47\%. Berdasarkan penilaian kepraktisan oleh siswa X IPS SI-SJ 2 maka sumber belajar geografi berbasis blog termasuk kategori sangat praktis.

\section{b. Analisis Data Kepraktisan Oleh Guru Geografi}

Tabel 6 Hasil Penilaian Kepraktisan Guru

\begin{tabular}{|c|c|c|}
\hline Aspek & $\begin{array}{c}\text { Nilai } \\
\text { Akhir }\end{array}$ & Kriteria \\
\hline Kelayakan Isi & 79,17 & Praktis \\
\hline $\begin{array}{c}\text { Efisiensi } \\
\text { Waktu }\end{array}$ & 87,50 & $\begin{array}{c}\text { Sangat } \\
\text { praktis }\end{array}$ \\
\hline Manfaat & 85,42 & $\begin{array}{l}\text { Sangat } \\
\text { praktis }\end{array}$ \\
\hline & $\mathbf{8 3 , 0 4}$ & Sangat \\
\hline
\end{tabular}




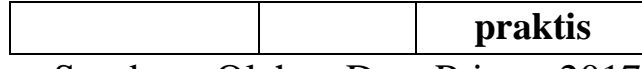

Sumber : Olahan Data Primer 2017

Berdasarkan tabel 6 dapat diketahui bahwa aspek kemudahan penggunaan $(79,17 \%)$ mendapatkan kategori praktis, aspek efesiensi waktu $(87,50 \%)$ dengan kategori sangat praktis, dan aspek manfaat $(85,42 \%)$ sangat praktis dengan nilai akhir 83,04\%. Berdasarkan penilaian kepraktisan oleh guru maka sumber belajar geografi berbasis weblog termasuk kategori sangat praktis.

Prosedur penelitian dan pengembangan produk ini diadaptasi dari model pengembangan ASSURE dengan beberapa langkah pengembangan yang dilakukan yaitu 1) analyze learners, 2) state objective, 3) select methods, media dan materials, 4) utilize materials, 5) require learners participation, dan 6) evaluated and revise

Hasil validasi diperoleh dari instrumen validitas yang diisi oleh dosen sebagai ahli perangkat pembelajaran, ahli materi dan media. Hasil validasi menunjukkan bahwa sumber belajar geografi berbasis weblog sangat valid untuk digunakan sebagai sumber belajar geografi. Sumber belajar geografi berbasis weblog layak digunakan sebagai sumber belajar karena telah memiliki kelayakan pada komponen isi/materi, kebahasaan, penyajian, dan kegrafisan yang baik. Hal ini sesuai dengan teori yang dinyatakan oleh Depdiknas (2008: 28) yang menyatakan bahwa kriteria penilaian validitas sebuah sumber belajar harus mencakup komponen evaluasi analisis isi, kebahasaan, sajian dan kegrafisan.

Berdasarkan hasil yang diperoleh dari uji validitas, belum semua komponen penilaian mencapai kategori sempurna. Berdasarkan saran dan tanggapan yang diberikan oleh validator ahli materi maka dilakukan revisi terhadap sumber belajar geografi berbasis weblog. Revisi yang dilakukan menyangkut kelengkapan materi, kejelasan gambar yang sesuai dengan fakta, tata cara penulisan (jenis huruf dan ukuran huruf yang digunakan), pemilihan warna dan background yang digunakan.

Hasil kepraktisan sumber belajar geografi berbasis weblog diperoleh dari instrumen kepraktisan yang diisi oleh dua orang guru geografi dan 30 siswa kelas X. Hasil Hasil uji kepraktisan oleh guru geografi bahwa sumber belajar geografi berbasis weblog sangat praktis untuk digunakan sbagai sumber belajar. Hasil penelitian ini sesuai dengan teori yang dijelaskan oleh Nana Sudjana dan Ahmad Rivai (2002:24) bahwa manfaat media pembelajaran dalam proses belajar yaitu pembelajaran dapat memanfaatkan media pembelajaran akan lebih menarik perhatian siswa sehingga dapat menumbuhkan motivasi belajar pada siswa tersebut.

\section{PENUTUP}

Berdasarkan hasil penelitian pengembangan sumber belajar geografi berbasis weblog pada materi kelas $\mathrm{X}$ SMA dapat disimpulkan bahwa: (1) Pengembangan sumber belajar berbasis weblog pada materi kelas X SMA 
melalui enam tahap yaitu analisis karakter siswa/analyze learners, menetapkan tujuan pembelajaran/state objective, memilih media, metode, dan bahan ajar/select methods, media, and materials, memanfaatkan bahan ajar/utilize materials, melibatkan siswa dalam kegiatan pembelajaran/require learnersandparticipation, evaluasi dan revisi/evaluated and revise. (2) Tingkat kevalidan sumber belajar geografi berbasis weblog diketahui dari ahli perangkat pembelajaran, ahli materi dan ahli media. Penilaian dari ahli perangkat pembelajaran mendapatkan nilai akhir 90,74\% dengan kategori "sangat valid", penilaian dari ahli materi mendapatkan nilai akhir 90,56\% dengan kategori "sangat valid", dan penilaian dari ahli media mendapatkan nilai akhir $85,42 \%$ dengan kategori "sangat valid". (3) Tingkat kepraktisan sumber belajar geografi berbasis weblog diketahui dari guru geografi SMA Negeri 8 Padang dan siswa kelas X IPS SI SJ 2. Penilaian kepraktisan dari guru mendapatkan nilai akhir 83,04\% dengan kategori "sangat praktis" dan kepraktisan dari siswa mendapatkan nilai akhir 83,47\% dengan kategori "sangat praktis

Berdasarkan penelitian pengembangan sumber belajar geografi berbasis weblog sebagai sumber belajar geografi pada materi kelas X SMA masih memiliki banyak kelemahan. Oleh karena itu, beberapa saran pemanfaatan dan pengembangan produk lebih lanjut yang dibutuhkan adalah (1) Penggunaan sumber belajar geografi berbasis weblog sebagai sumber belajar diharapkan agar dapat memanfaatkan produk pembelajaran weblog ini selama materi yang disajikan didalamnya masih relevan. Memberikan kontribusi dengan mengupdatebeberapa materi jika diperlukan. (2) Penggunaan weblog sebaiknya diakses tidak hanya pada saat jam pelajaran geografi saja, namun dapat diakses kapanpun dan dimanapun.

(3) Perlu menambahkan dengan kuis interaksi agar siswa lebih tertantang mengerjakan latihan.

\section{DAFTAR PUSTAKA}

Depdiknas. 2008. Panduan Pengembangan Bahan Ajar. Jakarta : Depdiknas.

Gwen Solomon Dan Lynne Schrum. 2011. Web 2.0. Jakarta: Pt Indeks Jakarta

Soeharto Karti. (1995). Teknologi Pembelajaran: Pendekatan sistem, Konsepsi dan Model, SAP, Evaluasi, Sumber Belajar dan Media. Surabaya: Surabaya Intelectual Club.

Nofrion. 2017. EXO OLO-Task Learning Model: An Introduction To Hots-Oriented Learning Model Based On Lesson Study. Journal of Education and Practice (Vol 8, No 28). 162-170.

NOFRION, N; WIJAYANTO, Bayu. LEARNING ACTIVITIES IN HIGHER ORDER THINKING SKILL (HOTS) ORIENTED LEARNING CONTEXT. Geosfera Indonesia, [S.1.], v. 3, n. 2, p. 122-130, aug. 2018. ISSN 2614-8528 
N Nofrion et al. 2018. IOP Conf. Ser.:

Earth Environ. Sci. 145012038

Permendikbud Nomor 22 Tahun 2016

tentang Standar Proses.

Riduwan. 2009. Belajar Mudah Penelitian Untuk Guru,

Karyawan dan Peneliti Pemula. Bandung: Alfabeta.

Nana Sudjana dan Ahmad Rivai. 2002. Media Pengajaran. Bandung: CV Sinar Baru

Sugiyono. 2008. Metode Penelitian Kuantitatif, Kualitatif Dan R\&D. Bandung: $\quad \mathrm{CV}$. Alfabeta

Warsita, Bambang. 2008. Teknologi Pembelajaran Landasan dan Aplikasinya. Jakarta: Rineka Cipta 